\title{
Secondary Brain Vesicle
}

National Cancer Institute

\section{Source}

National Cancer Institute. Secondary Brain Vesicle. NCI Thesaurus. Code C34290.

Subdivisions of the developing embryonic neural tube, including the telencephalon, diencephalon, mesencephalon, metencephalon and the myelencephalon, that are formed by the partition of the three primary brain vesicles. 